\title{
Prevalence of Bovine Trypanosomosis its Associated Risk Factors, and Tsetse Density in Bonke Woreda, Gamo Zone, Ethiopia
}

\author{
Firew Lejebo ${ }^{1 *}$, Awassa Atsa ${ }^{2}$, Mogos Hideto ${ }^{1}$, Tesfaye Bekele ${ }^{2}$ \\ ${ }^{1}$ National institute for Control and Eradication of Tsetse and Trypanosmiasis, Arba Minch Station, Arba \\ Minch, Ethiopia \\ ${ }^{2}$ Wolyta Soddo University College of Veterinary Medicine.
}

*Corresponding Author: Firew Lejebo, National institute For Control and Eradication of Tsetse and Trypanosmiasis, Arba Minch Station, Arba Minch, Ethiopia.

\begin{abstract}
A cross-sectional study under taken from January, 2019-Jun, 2019 in Durbe and Demebile ossa kebeles of Bonke district, Gamo Zone, South nation nationalities and people region state (SNNPRS), Ethiopia. The objective of study was to determine the prevalence of trypanosomiasis, associated risk factors for the occurance of the disease, and tsetse density in the area. A simple random sampling method was used to collect blood samples from 384 scattle and analyzed using conventional hematological and parasitological techniques. The overall prevalence of trypanosome infection in the study area was $1.82 \%$ (7/384).

However, there was no a statistical variation among the two districts ( $p>0.05$ ). Most of the infections were due to Trypanosoma congolense (1.30\%) followed by Trypanosoma vivax (0.52\%). This study showed a significant $(p<0.05)$ in trypanosoma infection rate among body condition and skin color of animals. The prevalence recorded was $0.52 \%$ for males and $1.3 \%$ for females without significant variation (P>0.05). Again the prevalence among young and adult animals was assessed with a recorded of $0.52 \%$ for young and $1.3 \%$ for adults animals and there was no statistically significant difference among age groups $(p>0.05)$. The prevalence of disease among parastemic and aparasitaemic animals was recorded as $1.82 \%$ and $0 \%$, respectively. In each study area, entomological surveys were conducted using $10 \mathrm{NGU}$ trap with 5 trap in Dembele ossa and Durbe PAs and Glossin pallidipes were the only tsetse fly species caught in the study area along with other biting flies; Stomoxys, tabanus and other different flies. Over all apparent density of the mean tsetses and biting flies of 1.6 and 6.53 were recorded respectively. Due to huge economic loss by this disease strict vector control techniques in complementary with sterile insect technique should be undertaken for eradication and to increase production and productivity for the farmers.
\end{abstract}

Keywords: $N G U$,Biting, tsetse flies, apparent density,prevalence and Trap.

\section{INTRODUCTION}

Tsetse-transmitted trypanosomiasis is one of the most ubiquitous and important constraints to agricultural development in the sub-humid and humid zones of Africa. Kuzoe (1991) estimated that about 50 million people are at risk of contracting African human trypanosomiasis. Reid et al. 1997 estimate that about 46 million cattle are at risk of contracting tsetse-transmitted trypanosomiasis in an area of about 8.7 million $\mathrm{km} 2 \ldots$ Winrock (1992) judge that the sub-humid zone and wetter portions of the semi-arid zone areas in which the greatest numbers of cattle are at risk of contracting the disease hold the continent's greatest potential for expansion of agricultural output.

Livestock is backbone of the socio economic system (trypanosome) found in the blood and other tissues of most of the rural communities of Africa (Elnasri, 2005). Ethiopia is known for its large and diverse livestock resource endowments. Livestock is primarily kept on small holdings where it provide drought power for crop production, manure for soil fertility and fuels, serves as a sources of family diet and sources of cash income (from livestock and livestock products). Despite large livestock population, Ethiopia fails to optimally utilize this resource due to different constrains facing the livestock subsector. Shortage of nutrition, reproductive insufficiency, management constraints and animal disease are the major constraints (Bekele etal, 2010). One of the diseases hampering the 
Prevalence of Bovine Trypanosomosis its Associated Risk Factors, and Tsetse Density in Bonke Woreda, Gamo Zone, Ethiopia

livestock subsector is trypanosomosis. Arba Minch tsetse control project has made intensive tsetse suppression activities for the last eight years in Bonke woreda. In order to check the present situation of the disease and vector density a study was made in two kebeles of Bonke woreda.

Based on the present study a new strategey for suppression intervention will be directed to give relief to the community from the disease and to prepare a new approach for the eradication of the disease based on rolling carpet principle of tsetse control. Therefore, the objectives of the study are:

- To determine the prevalence of trypanosomiasis and tsetse density in bonke woreda.

- To determine associated factors for occurance of trypanososmiasis.

\section{LITERATURE REVIEW}

In Ethiopia, trypanosomosis is one of the major impediments to livestock development and agricultural production contributing negatively to the overall development in agriculture in general and to food self reliance efforts of the nation in particular. While tsetse borne trypanosomosis is excluding some $200,000 \mathrm{~km} 2$ of agriculturally suitable landing the west and south west of the country, 14 million heads of cattle, an equivalent number of small ruminants, nearly 7 million equines and 1.8 million camels are at risk of contracting typanosomosis at any one time (Langridge, 1976; MoARD, 2004; STEP, 2013).Trypanosomosis is a complex disease caused by unicellular parasites (trypanosomes) found in the blood and other tissues of vertebrates including cattle and man (Tesfaye, 2002; Uilenberg, 1998). The diseases are caused by flagellate protozoa called trypanosomes, which are transmitted by a number of different arthropod vectors but mainly by biting flies (Urquhart et al., 1996). The most important trypanosome species affecting livestock in Ethiopia are Trypanosoma congolense, Trypanosoma vivax and Trypanosoma brucei, in cattle, sheep and goats, Trypanosoma evansi in camels and Trypanosoma equiperdium in horses (Getachew, 2005). Three elements influence the epidemiology of the disease, namely the distribution of the vectors, the virulence of the parasite (trypanosome) and response of the host (Urquhart et al., 1996).Tsetse flies (the vector) are in the genus Glossina species, Glossina morsitans usually is found in savanna country, Glossina palpalis prefers areas around rivers and lakes and Glossina fusca lives in high forest areas. All three species transmit trypanosomes in various mammals (Aiello and Mays, 1998) and also biting flies may act as mechanical vectors, which requires only that blood containing infectious trypanosomes to be transferred from one animal to another but their significant in Africa is still undefined. In the case of T. vivax, Tabanus species and other biting flies seem to be the primary mechanical vectors (Aiello and Mays, 1998). The life cycle of trypanosome is complex in both tsetse fly vector and the mammalian host; trypanosomes undergo a series of transformations into different forms (Seifert, 1996). Most tsetse-transmission is cyclical and begins when blood from a trypanosome infected animals are ingested by the fly. The trypanosome losses its surface coat, multiplies in the fly, then reacquire a surface coat and becomes infective. T. brucei species migrate from the gut to the proventriculus to the pharynx and eventually to the salivary glands; the cycle for $T$. congolense stops at the hypopharynx and the salivary glands are not invaded; the entire cycle for $T$. vivax occurs in the proboscis. The animal infective form in tsetse salivary gland is referred as the metacyclic form. The lifecycle in the tsetse may be as short as one week with T. vivax or extend to a few weeks for T. brucei species (Aiello and Mays, 1998)

The clinical signs of the disease depend up on the species and strain of trypanosome, the vector and resistance of the affected breed animal. Trypanosomosis can be diagnosed based on either detection of the parasite by the light microscope (parasitological) or demonstration of the circulating antibody (serological) in conjunction with clinical observation (Paris et al., 1979). The stained thin blood smears afford the best means of identifying species of trypanosomes (Stephen, 1986). Tsetse control currently relies on two bait systems; the first is trap and targets, which are treated with insecticide which kills tsetse on contact. The second is insecticide treated livestock. Both systems have little direct damage to the environment (Vale, 1993) and of being very effective if applied properly in the appropriate circumstances. 
Prevalence of Bovine Trypanosomosis its Associated Risk Factors, and Tsetse Density in Bonke Woreda, Gamo Zone, Ethiopia

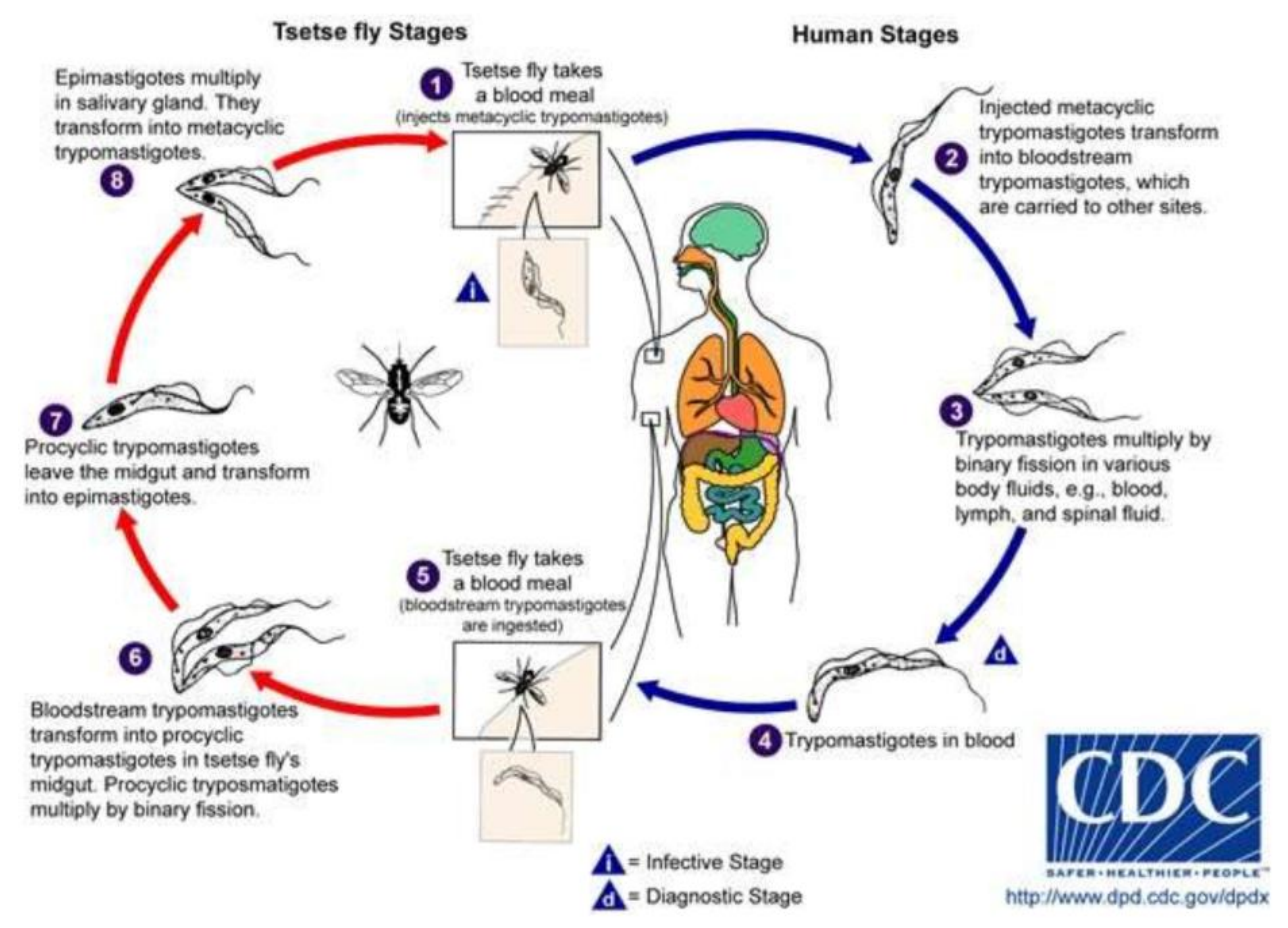

Figure1. Life cycle of trypanosome species between tsetse fly and human (WHO, 2000).

\subsection{Morphology and Life Cycle of Tsetse Fly}

\subsubsection{Morphology of Tsetse Fly}

Tsetse flies are elongated and robust, of various shades of brown ranging from yellowish to grayish to dark or blackish brown but never metallic. The males are usually smaller than the females (Mulligan, 1970). When the fly is at rest the wings overlap one over the other. In the middle of each wing there is distinctive shape, which is a powerful imagination can compel with a butcher's cleaver with edge facing forwards. This is called a "hatchet cell" and is a useful diagnostic character which may make it possible to identify badly managed specimens as being certainly Glossina (Soulsby, 1992; Itard, 1981). The males are readily distinguished by the presence of hypopygium centrally at the tip of the abdomen. It is said that the male's eyes are larger, or alternatively that the space between the eyes is smaller, but this character is not distinctive enough for field use (Mulligan, 1970).

\subsubsection{Life Cycle of Tsetse Fly}

As in other Dipteral, the female has a pair of spermathecae in which sperm acquired very early in life is stored and lasts the female's life span. The two sexes emerge in equal numbers; it follows that if one mating per life is usual in females, a male must on average mate only once. Females usually mate at the age of 2-3 days and the males after age of 7-8 days. During copulation, the sperm are transferred from the male to the uterus of the female. As the egg of a female fly passes from the ovary into the uterus it is fertilized by sperm, which pass down the duct from spermathecae (where they are stored after copulation) to the uterus. The egg hatches in the uterus and the first instars larvae feeds by mouth on a secretion produced by milk gland. After a molt, the second instars larvae continue to feed on the same milk. After the second molt the larva is extruded, it is now in its third instars and weighs nearly as much as its mother (Mulligan, 1970). The third instars larvae have respiratory lobes called polypneustic lobes and it burrows and hides in the soil and assumes the shape of the barrel, its integument becomes rigid and darkens and is now known as a puparium. Within the puparium two moults take place, the first produces the pupa and the second the imago, a process often called eclosion of the adult (Newstead et al., 1924). The pupa stage lasts 2-13 weeks. It depends on temperature and humidity. Emergence from puparium takes place between 12:00 and18:00 hrs that is within a few hours of the daily maximum temperature. This rhythm is maintained under conditions of constant temperature but displaced if the temperature rhythm is altered. On emergence the wings are crumpled, but they are expanded in about five minutes and the tsetse can fly in an hour or two (Mulligan, 1970; Newstead et al., 1924). 


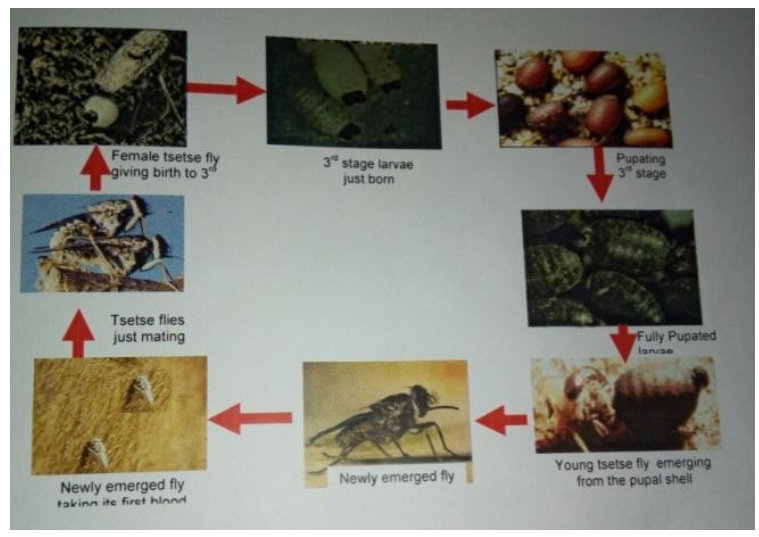

Figure2. Life cycle of tsetse flies(Leak,1987)

\subsection{The Distribution, Habitat and Importance of Tsetse Fly in Africa}

The limits of Glossina distribution are determined primarily by the climate and secondly by the vegetation, which can often mitigate the severity of climate. It could be observed that the huge central tsetse area is bounded by country having less than twenty inches of rainfall. The area with over sixty inches of rain per annum which extends along the coast of longitude $300 \mathrm{E}$; this is the area of equatorial forest. Surrounding it is a vastarea, with sixty to twenty inches of rainfall, which is wood land savannah or grass land. The broad picture of rain forest surrounded by savannah, ending in desert or the sea, should be remembered, as the distribution of the different species of tsetse is closely related to it. Nevertheless, it must be appreciated that the great forest belt used to be far more extensive than it is now and that relict forest and forest species of tsetse still occur well outside the limits suggested by the over sixty inch rainfall zone. There are other localized areas of forest, such as those found around mountains and down the east coast of Africa, which are hundreds of miles from the great equatorial forest belt and unrelated to it (Langridge, 1976; Ford, 1971).

\subsection{The Distribution of Tsetse Flies in Ethiopia}

According to survey result conducted by Langridge (1976), five species of tsetse flies were found and identified in Ethiopia as: the Fusca group: G. longipennis, the Moristans group: G. m. submoristans and $G$. pallidipes and the Palpalis group: G. fucipes and G. tachinoides. The fly belts (infested areas) in Ethiopia extend from the southern part of the rift valley, around the southwestern corner of the country and along the western lowland and escarpment to the Abay River (Langidge, 1976).

\section{G. M. Submoristans}

In the 1970 it was found in Didessa valley near the villages of Wonago and Lado on the eastern side of Lake Abaya, the Amaurou village in Shambo sub district, on the Abay near Deru village on the Mugher River in Shoa province, on the Dabous River in Wollega, on the Baro and Gilo Rivers in Gambella district, Illubabor, in the Savannah near Turmi in South Gamu Gofa, and near Mizan Teferi in Keffa province (Langridge, 1976). According to Langridge (1976), its infestation was associated with Abay (Blue Nile) River. G. $m$ submoristans in Wollega was associated with the southern border of the province and Baro River at its tributaries. The main areas of its infestation in Illubabor were associatedwithAkobo(Langridge,1976).

\section{G. Pallidipes}

In 1970, it was recorded from lower Omo River and on the Woitto River and at Keiafer (1550 m asl) also near Bako in Gamu Gofa province. It was found along the Sagan River near Lake Chamo in Gemu Gofa. The whole of the Omo Bottego was infested with G. pallidipes. The Gojeb was also infested with $G$. pallidipes and this infestation extended about $20 \mathrm{~km}$ above the bridge on the Jimma to Bonga road. The lower Omo was also infested with this species up to down wards as far as Omorate. The areas in Gamu Gofa are divided in to two parts concerning tsetse infestation. The division is formed by the strip of highlands which runs from north to south wards (Langridge, 1976). The eastern part is comprised of the southern rift valley and Sugan river system. This area was infested

with G. pallidipes. It was said that quite4 possible that G. pallidipes in Rift valley is connected with those in Omo River area. The link is likely to be across the narrow strip which separates the upper part of the Galana Dulei valley (Woitto) with the Maze River valley (Daramalo). It was predicted that 
Prevalence of Bovine Trypanosomosis its Associated Risk Factors, and Tsetse Density in Bonke Woreda, Gamo Zone, Ethiopia

unlikely G. pallidipes will spread much further in the rift valley beyond its limits with exception of the north ward movement along the western side of Lake Abaya. G. pallidipes infestation in Sidamo extended from lower Gidabo River down the eastern sides of Lake Abaya and Chamo to the Sagan River along which it extends to Lake Chew Bahir. This eastern belt also includes the large Galana River valley between Amaro Mountains and the southern highlands. It had reached the limit of its movement eastwards to the southern high lands where it was prevented from going any further by the mountains. This species had extended along the southern border of Wollega and associated with Baro River vegetation and its upper tributaries (Langridge, 1976).

\section{G. Fuscipes}

During early time the presence of G. fuscipes was recorded in 1901 and in 1938, and in 1970 recorded from the Maze, Gorgora, Bazo and Cuccia Rivers in Gamu Gofa, on the Ketto tributary of the Birbir and at Degeno on the Birbir in Wellega, on the that tributary of the Gojeb in Kaffa and near the bridge on the Omo River, Addis Gimma high way. The Ghibe is only infested with G. fuscipes as other species have found above the bridge. The whole upper and lower Omo also were infested with it (Langridge,1976).

\section{G.Tachnoides}

It was found along the Abay (Blue Nile) River system. It also had infested the Belles River valley. It was predicted that it may be able to spread along the gorge and infest the riverain vegetation up a far as Mota. In Akobo River system, G. fuscipes was replaced by G. tachnoides, where the river comes outintothelowlandplains(Langridge,1976).

\subsection{The Distribution of Tsetse Flies in the Omo Belt}

During the course of survey conducted by National Tsetse and Trypanosomosis investigation and Control Centre and by Sodo Regional Veterinary Laboratory, the distribution of tsetse and trypanosomosis were recorded in upper Omo belt. Tsetse species identified from this belt were G. $m$. submorsitans, G. fuscipes and G. pallidipes (SRVL, 2004).

\section{G. M. Submorsitans}

Its infestation was associated only with Omo River system. It seems that this species had spread from two sides: 1. Langridge (1976) in his report predicted that the species can spread south ward in the lower Omo valley from upper Akobo and then Maji which is tributary of lower Omo at west. Therefore, it seems through this area infestations took place to lower and middle Omo belt. 2. This species is also present on the Ghibe River system up to Gurage woredas in the south and its origin and route of spread to Ghibe Valley was not well known, but it seems that the invasion might be from Didessa belt (SRVL, 2004).

\section{G.Pallidipes}

the whole Omo belts which are indicated above are infested with G. pallidipes. In Omo belt it was associated with Gojeb and Ghibe River systems including middle and lower Omo River system (Birhanu,1999;SRVL,2004).

\section{G. Fuscipes}

It was found along the Omo River system. The whole Gojeb River and its tributaries and Omo River and its tributaries were also infested with G. fuscipes. It was also found along Ghibe and its tributaries (SRVL, 2004; Birhanu, 1995).

\subsection{The Distribution of Tsetse Flies in the Rift Valley}

In the rift valley only Glossina pallidipes were found. This makes easy eradication of tsetse flies from the area (ThomasandBerisha,2011).

\section{MATERIALS AND METHOdS}

\subsection{Description of the Study Area}

The entomological and parasitlogical data collection was undertaken from January, 2019-Jun, 2019 from Durbe and Demebile ossa kebeles of Bonke district, Gamo Zone, South nation nationalities and people region state(SNNPRS), Ethiopia. It has boundary in the south-east with Arbaminch Zuria, South-west with Alle woreda, West with Kamba, and on the North with Daramalo woreda. 
Prevalence of Bovine Trypanosomosis its Associated Risk Factors, and Tsetse Density in Bonke Woreda, Gamo Zone, Ethiopia

It is about $55 \mathrm{Km}$ a way from Arba Minch, Gamo zonal town. According to the Bonke woreda finance and economical development office (2011) the total populations of the woredas were estimated to be 81,025 . The agricaltural system practiced by rural community is mixed farming system where crop and livestock farming were practiced. The woreda commonly grows crops such maize, coffee, banana, papaya, mango, avocado, inset, barley, sorghum and sweet potato (Bonke woreda agricaltural office, 2011)

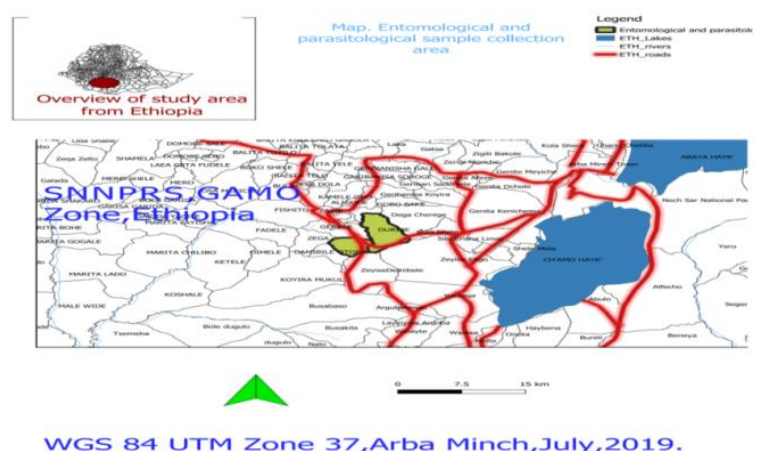

Figure3. Study area

\subsection{Study Design and Study Population}

Acrossectional study was conducted to determine the prevalence of bovine trypnosomiasis, associated risk factors and tsetse densities in Durbe and Dembile kebeles of Bonke Woreda. The study animals used for this study were cattles with differen sex, age, colour and body conditions. According to Radostits and Gray, the age of the animals were categorized as young ( $\leq 3$ years young) and adult (>3 years old).

\subsection{Sampling Method and Sample Size Determination}

Across-sectional study was conducted to determine the prevalence of bovine trypanosomosis and its vector density in selected areas purposively as convenient for the availability of tsetse and trypanosomiasis. The study animals were selected by using simple random sampling method by taking age, sex, body condition and coat color into account. Using simple random sampling methods lists of the owner together with the animals names were taken before the animals were entered into the crush for examinations. The examinations were made according to their order of list. The subjects were selected randomly from the population all the animals in the selected areas had equal chances to be selected for this study. The total number of animals required for the study was calculated based on the formula given by Michael Thrush field (2005). Since there was no previous work done in this area, the expected prevalence is $50 \%$, so that the sample size in this study is calculated using the following formula.

$$
N=\frac{1.96^{2}(p)(1-p)}{d 2}
$$

Where, $n=$ required sample size

$$
\begin{aligned}
& 1.96=\text { the value of } 95 \% \text { confidence interval } \\
& \mathrm{P}=\text { expected prevalence of trypanosomosis is } 50 \% \\
& \mathrm{D}=\text { desired absolute precision level at } 95 \% \text { confidence interval }(0.05) \text {. }
\end{aligned}
$$

Using the above formula 384 cattle was selected.

\subsection{Study Methodology}

\subsubsection{Entomological Data Collection}

For the entomological study, atotal of 60 NGU traps baited with phenol were deployed of which 30 were deployed in Durbe and the other 30 were deployed in Dembele ossa kebeles. After 72hours a fly collection and counting was made.(FAO, 1992). The apparent density (f/t/d) was calculated to determine the fly density and distribution (Leak et al., 1987). The species identification of tsetse fly using the standard procedures (Pollock, 1982) and biting flies according to their morphological 
Prevalence of Bovine Trypanosomosis its Associated Risk Factors, and Tsetse Density in Bonke Woreda, Gamo Zone, Ethiopia

characteristics such as size, color, wing venation structure, and proboscis at the genus level was made (Uilenberg, 1998)

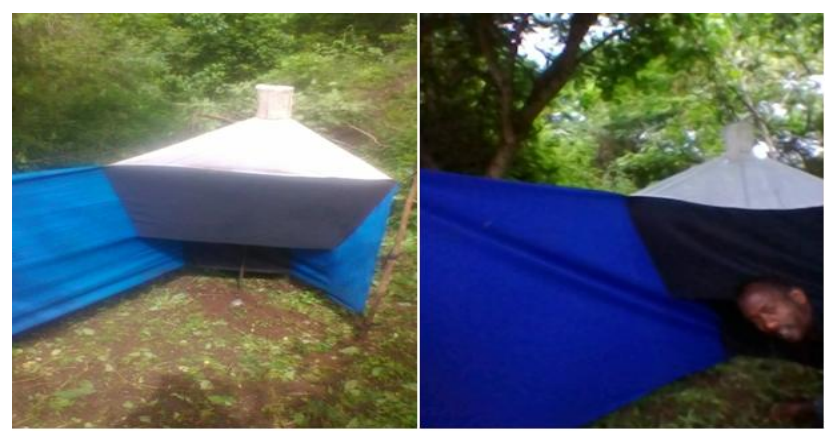

Figure4. NGU trap for entomological monitoring

\subsubsection{Parasitological examination}

For parasitological examination, blood sample were collected from ear vein of animal using microhaematocrit capillary tube until three-quarters of the length of the tube were filled and the other end of the tube was sealed over a by special wax and the tubes were then placed in the grooves (individually identified by a number corresponding to the number of the blood sample) of the rotor plate, with the sealed end outwards (to prevent the blood from being thrown out during centrifugation); the cover were closed and screwed down, and the timing was set for 5 minutes at $12,000 \mathrm{rpm}$. After centrifugation, the tubes were removed, the packed cell volume (PCV) value (the length of the column of concentrated cells, percentage of the total length of the blood column) read directly in a special reader, which were individually adjusted for the length of the blood column in each tube; the PCV gaves a valuable indication on the presence and degree of anaemia and the tube was then examined for the presence of trypanosomes making a smear of the buffy coat/plasma junction. The Buffy coat is poured on a slide and covered with a $22 \times 22 \mathrm{~mm}$ cover slip and examined using a microscope with a phase contrast and dark ground illumination (Murray et al., 1983).

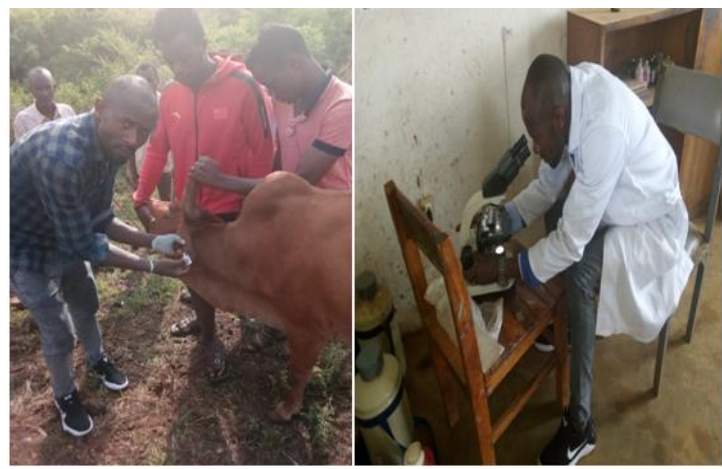

Figure5. Parasitological examination

\subsubsection{Factors that Affect Distribution of the Disease}

In this study age, sex, coat color, body condition and others were investigated in case they had an association with Trypanosomosis. Accordingly Nicholson and Butterworth (1986), animals were considered as poor when they show marked emaciation, transverse process project prominent, spines appear sharply, individual dorsal spines are pointed to the touch, hips, tail, head and ribs are prominent. Whereas animals categorized under good body condition score were animals with smooth, well covered and heavy deposits of fat, which is clearly visible on tail, head, brisket, dorsal spines, ribs and hooks and as medium when they are found between the two.

\subsection{Data Management and Analysis}

Microsoft Excel was used to store all the data and Stata version 14.2 were used to analyze the data. Statistical tests like the percentages and means were employed for data analysis. Parasitological (data on trypanosome prevalence) were analyze by applying chi-square test to evaluate the association with different variables like age, sex, color and BCS. The mean PCV values of anemeic and non anaemic animals were analyzed. In all cases differences between parameters was tested for significance at probability levels of 0.05 . 
Prevalence of Bovine Trypanosomosis its Associated Risk Factors, and Tsetse Density in Bonke Woreda, Gamo Zone, Ethiopia

\section{RESUlT}

\subsection{Parasitological Findings}

Trypanosome parasite was detected in $7 / 384$ cattle, which was $1.82 \%$ overall prevalence rate at study area. The prevalence of bovine trypanosomosis in the two peasant association (PAs) was determined to be $2.08 \%$ in Dembele otora and 1.56 in Durbe. There was no a statistical variation among the two districts $(\mathrm{p}>0.05)$.

Table1. Prevalence of Trypanosomiasis in two selected Pas with respect to species

\begin{tabular}{|l|l|l|l|l|}
\hline \multicolumn{5}{|c|}{ Trypanosome species } \\
\hline PAs & No of animals examined & TC & TV & prevalence rate \\
\hline Dembele ossa & 192 & 3 & 1 & 2.08 \\
\hline Durbe & 192 & 2 & 1 & 1.56 \\
\hline Total & 384 & 5 & 2 & 1.82 \\
\hline
\end{tabular}

\subsection{Risk Factors}

The risk factors considered were analyzed against trypanosome prevalence. Accordingly, PCV, age, sex, Pas, coat color of skin and body condition score were observed. Among these body condition score $(\mathrm{p}=0.001)$ and color $(0.009)$ showed significant difference in disease distribution $(\mathrm{p}<0.05)$. A Chi-square test was applied to evaluate the presence of association between disease and risk factors.

A PCV measurement of less than $25 \%$ was regarded as a threshold value and considered as parasitaemic and animals with a PCV measurement value of more than $25 \%$ is considered as aparasitaemic. Based on this finding, there is no significant difference between the value of pcv and the disease $(\mathrm{p}=0.095)$.

Table 2. The prevalence of trypanosomiasis based on PCV.

\begin{tabular}{|l|l|l|l|l|}
\hline \multirow{2}{*}{ PCV } & Result & Total & prevalence \\
\cline { 2 - 3 } & $-\mathrm{ve}$ & $+\mathrm{ve}$ & & \\
\hline parasitaemic & 269 & 7 & 276 & 1.82 \\
\hline aparasitaemic & 108 & 0 & 108 & 0 \\
\hline Total & 377 & 7 & 384 & 1.82 \\
\hline
\end{tabular}

The age of the animals was also considered as a one of the risk factor and whether the age difference has role on fly were assessed. Accordingly, young and old animals were observed. adult animals were assumed as attractive for tsetse. However, out of 384 animals examined, young animls 104(0.52\%) and 280(1.3\%) adult animals were positive for trypanosomosis but there were no significant difference among age groups $(\mathrm{p}=0.92)$.

Table3. The prevalence of trypanosomiasis based on age.

\begin{tabular}{|c|c|c|c|c|}
\hline \multirow{2}{*}{ age } & \multicolumn{2}{|c|}{ Result } & \multirow{2}{*}{ Total } & \multirow{2}{*}{ prevalence } \\
\cline { 2 - 3 } & -ve & +ve & & 0.52 \\
\hline young & 102 & 2 & 104 & 1.3 \\
\hline Adult & 275 & 5 & 280 & 1.82 \\
\hline Total & 377 & 7 & 384 & \\
\hline
\end{tabular}

The sex of the animals was also considered as a one of the risk factor and whether the sex difference has role on fly were assessed. Accordingly, male and female animals were observed. Accordingly, female animals were assumed as attractive for tsetse. However, out of 384 animals examined, female animals $227(1.3 \%)$ and $157(0.52 \%)$ male animals were positive for trypanosomosis but there were no significant difference among sex groups $(\mathrm{p}=0.50)$.

Table4. The prevalence of trypanosomiasis based on sex.

\begin{tabular}{|c|c|c|c|c|}
\hline \multirow{2}{*}{ Sex } & \multicolumn{2}{|c|}{ Result } & \multirow{2}{*}{ Total } & prevlence \\
\cline { 2 - 3 } & $-\mathrm{ve}$ & $+\mathrm{ve}$ & & 1.3 \\
\hline $\mathrm{F}$ & 222 & 5 & 227 & 0.52 \\
\hline $\mathrm{M}$ & 155 & 2 & 157 & 1.82 \\
\hline Total & 377 & 7 & 384 & \\
\hline
\end{tabular}

The color of the animals was also considered as a one of the risk factor and whether the color difference has role on fly attraction or not was assessed. Accordingly, white, black and red colored animals were observed. Black colored animals were assumed as attractive for tsetse to rest. However, 
Prevalence of Bovine Trypanosomosis its Associated Risk Factors, and Tsetse Density in Bonke Woreda, Gamo Zone, Ethiopia

out of 384 animals examined, 78(0\%) white colored, $183(0.26 \%)$ red and $123(1.56 \%)$ Black. Black colored group were positive for trypanosomosis and statistically were significant $(\mathrm{p}<0.05)$ among the skin color of tested animals.

Table5. The prevalence of trypanosomiasis based on colour

\begin{tabular}{|c|c|c|c|c|}
\hline \multirow{2}{*}{ Colour } & \multicolumn{2}{|c|}{ Result } & Total & Prevalence \\
\cline { 2 - 3 } & $-\mathrm{ve}$ & $+\mathrm{ve}$ & & 1.56 \\
\hline Black & 117 & 6 & 123 & 0.26 \\
\hline Red & 182 & 1 & 183 & 0 \\
\hline White & 78 & 0 & 78 & 1.82 \\
\hline Total & 377 & 7 & 384 & 0 \\
\hline
\end{tabular}

Based on their body condition score, study animals were categorized into good, medium and poor body conditions. Of the total animals examined, 145(0\%), 140(0.26\%) and $99(1.56 \%)$ prevalence was observed in good, medium and poor body condition respectively and there was significant difference $(\mathrm{p}<0.05)$ between body condition scores.

Table6. The prevalence of trypanosomiasis based on body conditions score

\begin{tabular}{|c|c|c|c|c|}
\hline \multirow{2}{*}{ BCs } & \multicolumn{2}{|c|}{ Result } & \multirow{2}{*}{ Total } & \multirow{2}{*}{ prevalence } \\
\cline { 2 - 3 } & $-\mathrm{ve}$ & $+\mathrm{ve}$ & 145 & 0 \\
\hline Good & 145 & 0 & 140 & 0.26 \\
\hline Medium & 139 & 1 & 99 & 1.56 \\
\hline Poor & 93 & 6 & 384 & 1.82 \\
\hline Total & 377 & 7 & \\
\hline
\end{tabular}

\subsection{Entomological Findings}

A total of 196 flies were caught at the time of the study; out of these 48 belong to tsetse flies and the remaining belong to biting flies, namely Tabanus, Stomoxys and other flies with a totsl catch of 78, 54 and 64 respectively. Only Glossina pallidipes (GP) species have been identified at study site. The overall apparent density (fly/ trap/ day) of tsetse and biting flies obtained in the study area was 1.6 and 6.53 respectively by. Therefore, the overall apparent density of biting fly was found to be higher than tsetse fly.

Table7. The apparent density of tsetse and biting flies in study site

\begin{tabular}{|c|l|c|c|c|c|c|c|c|c|c|c|}
\hline $\begin{array}{c}\text { Trap } \\
\text { ID }\end{array}$ & SPP. & M & F & Unsex & Total & ftd & \multicolumn{5}{|c|}{ Biting flies } \\
\cline { 8 - 13 } & & & & & & & & & & & \\
TD 1 & G.pallidepes & 2 & 1 & 1 & 4 & 1.33 & 10 & 5 & 2 & 17 & 5.66 \\
\hline TD 2 & G.pallidepes & 2 & 1 & 1 & 4 & 1.33 & 13 & 9 & 14 & 36 & 12 \\
\hline TD 3 & G.pallidepes & 4 & 2 & 0 & 6 & 2 & 9 & 7 & 10 & 26 & 8.66 \\
\hline TD 4 & G.pallidepes & 3 & 2 & 0 & 5 & 1.66 & 6 & 8 & 12 & 26 & 8.66 \\
\hline TD 5 & G.pallidepes & 2 & 1 & 0 & 3 & 1 & 9 & 4 & 5 & 18 & 6 \\
\hline TDO 6 & G.pallidepes & 1 & 2 & 3 & 6 & 2 & 10 & 4 & 5 & 19 & 6.33 \\
\hline TDO 7 & G.pallidepes & 0 & 0 & 5 & 5 & 1.66 & 4 & 4 & 5 & 13 & 4.33 \\
\hline TDO8 & G.pallidepes & 1 & 0 & 3 & 4 & 1.33 & 5 & 5 & 4 & 14 & 4.66 \\
\hline TDO9 & G.pallidepes & 2 & 1 & 3 & 6 & 2 & 4 & 4 & 4 & 12 & 4 \\
\hline TDO10 & G.pallidepes & 1 & 1 & 3 & 5 & 1.66 & 8 & 4 & 3 & 15 & 5 \\
\hline Total & & 18 & 12 & 18 & 48 & 1.6 & 78 & 54 & 64 & 196 & 6.53 \\
\hline
\end{tabular}

$\mathrm{TD}=\operatorname{Durbe}(\mathrm{ftd}=1.46)$

$\mathrm{TDO}=$ Dembele ossa $(\mathrm{ftd}=1.73)$

\section{DISCUSSION}

The present study revealed that from a total of 384 randomly selected cattle in study area, $7(1.82 \%)$ of them were positive for trypanosome, out of which 3 (1.56\%) in Durbe and 4 (2.08\%) in Dembele ossa, was recorded (Table.1). Generally, more prevalence of the disease was found in place where highest tsetse fly density is present (Table- 7). This result is in agreement with previous result obtained by Girma. K.etlal, 2018 who conclude that both the apparent density and prevalence of trypanosomes are positively correlated. The present study revealed $1.82 \%$ trypanosome infection which is lower when compared to that of Megersa etal, 2019 at Jimma zone which is $12.24 \%$. The 
Prevalence of Bovine Trypanosomosis its Associated Risk Factors, and Tsetse Density in Bonke Woreda, Gamo Zone, Ethiopia

reason for reduction of the flies was variouse tsetse control acivities undertaken by Arba Minch tsetse and trypanosomiasis control station such as chemical application on the back of the animals, insecticide impregnated targets, ground spraying and aerial spray which significantly reduces the prevalence of disease in the study area. The other reason for the low prevalence of the disease might be the widely use of trypanocidal drugs as prophylactic agent. The present study in terms of trypanosome species, $1.3 \%$ and $0.52 \%$ T.congolense and T.viva respectively. This result is in agreement with with that of K. Girma etlal, who reported $0.8 \%$ T. congolonse and $0.5 \%$ T. vivax infection, respectively.

This finding is in disagreement with Sinshaw et. al., 2006 indicated a prevalence of trypanosomosis ranging from $4 \%$ to $9.6 \%$ due to T. vivax in the three highland districts bordering Lake Tana (Table1). Regarding PCV (Table.2) the present study showed that most of the parasitemic animals (100\%) were found to be anemic (PCV $\leq 25 \%)$ compared with aparasitemic (PCV> 25\%) animals $(0 \%)$. This is in agreement with Thrusfield, 2005 stated that average PCV of parasitologically negative animals was significantly higher than those of parasitologically positive animals. Therefore, trypanosomosis may lower the PCV value of infected animals during the study period. The prevalence of bovine trypanosomosis was assessed between sexes of animals (Table 4) and among the 5 animals positive for trypanosomiasis; $3(1.3 \%)$ of them were found in female animals and $2(0.52 \%)$ of them were found in male animals; this shows that almost both male and female cattle were equally susceptible to trypanosomosis infection. This result is similar with previous results of. Girma K etlal, 2018 who obtained no significant difference in susceptibility between the two sexes. In contrast it is in disagreement with Muturi, 1999 reported that males had higher prevalence of trypanosomosis than females. This might be due to grazing conditions for male animals than females related to their physiological situations. During the study the prevalence of bovine trypanosomosis was assessed in three different body condition (Table.6) (poor, good and medium) animals' shows the highest prevalence in poor body condition $(1.56 \%)$ followed by in medium $(0.26 \%)$ and good body condition $(0 \%)$. Due to poor body condition; animals are highly susceptible to diseases. This result is consistent with the report made by Basaznew et al., 2012 in which they reported 55.7\%, 0\% and 6.7\% prevalence in poor, good and medium body condition score respectively.

Comparison conducted between the different skins color of cattle (Table.5) indicated that higher prevalence was observed in cattle's having black skin color $(1.56 \%),(0 \%)$ in white and $(0.26 \%)$ in red. By nature tsetse flies are attracted toward a black color, so in animals having black color, there was high prevalence of trypanosomosis recorded. The finding is in agreement with the report of Degu et al.,2012 in which the prevalence rate was $12.4 \%, 5.17 \%$ and $3.23 \%$ in black, red and white skin color of cattle respectively. The animals examined were categorized in two age groups as young ( 3 years old) and adults ( $>3$ years old). The trypanosome infection prevalence was found to be $0.52 \%$ in the young age group and $1.3 \%$ in the adult animals (Table.3). However, statistically there is no significant difference in infection rate among the different age groups $(p>0.05)$. These results agree with that of Dagnachew and Shibeshi, 2006 as a higher prevalence was observed in adult animals ( $>3$ years) and but lower in animals 3 years of age. This could be associated to adult animals are easily visible to tsetse flies than small animals. This is in agreement who stated that calves and young animals have low prevalence Fimmen etlal, 1992. From the study of Leak et al. 1987, it is known that the variation in tsetse density appeared to be the main factor for variation in the prevalence of trypanosomosis(Table1). The overall apparent density of tsetse fly and biting fly obtained in the study area was 1.6 and 6.53 respectively.

\section{CONCLUSION AND RECOMMENDATION}

The present study has shown that trypanosomosis is less prevalent in the study area than the other areas with similar condition for tsetse breeding. Due to deforestations areas for tsetse breeding were cleared and hence result in low prevalence of the disease. For the last thhree years a lot of planting of trees were undertaken in the area which can gradually create conducieve environment for tsetse breeding which inturn result in the reinvasion of tsetse flies. Therefore, the exsiting prevalence of trypanosomosis in association with the conducieve environment supposed to be creaed might result in economic loss through reduced weight gain; reduce drought power, increased treatment cost and death of affected animals. In the study area, T.conglonse and T.vivax were the only species affecting cattle, and the skin color and body conditions of the animals had significant relationship to the disease. An overall apparent density of tsetse fly and biting flies at study site was 1.6 flies and 6.53 respectivelly. 
Prevalence of Bovine Trypanosomosis its Associated Risk Factors, and Tsetse Density in Bonke Woreda, Gamo Zone, Ethiopia

During entomological survey, only one species (G. pallidipes) of tsetse fly and biting flies such as stomoxys, tabanus and other were identified. Based on the above findings, the following recommndations are forwarded.

Strict vector control techniques in complementary with sterile insect technique should be undertaken to protect reinvasion to the cleared areas as well as to increase productivity to the livestock sector. Longitudinal study should be undertaken so as to see different factors other than those included in this research to obtain full data about the disease and the flies.

\section{REFERENCES}

[1] Aiello E, Mays A (1998). Tsetse transmitted Trypanosomosis. In: Merck Veterinary Manual,eighth edition. Merck and co.,Inc.

[2] BWFECO (2011): Annual report of Bonke woreda finance and economic development office,Gamo Zone, SNNPRS, Ethiopia.

[3] Bonke Woreda Agricultural office (2011): Annual reports, Bonke Woreda Agricultural office Gamozone, Southern nation nationalities and peoples reginal state Ethiopia.

[4] Birhanu, A. (1995). Preliminary survey on tsetse distribution and prevalence of bovine trypanosomosis in selected weredas of North Omo and Kembata Alaba Tambaro zones. AAU, Faculty of Veterinary Medicine, Debre Zeit, DVM Thesis.

[5] Bekele, J., K. Asmare, G. Abebe, G. Ayelet and G. Esayas, 2010. Evaluation of Deltamethrin applications in the control of tsetse and trypanosomosis in the southern rift valley areas of Ethiopia. Vete Parasitol., 168: 177-184.

[6] Basaznew, B., Ch. Mersha and Chemirew Arega, 2012. Hematopathology and Hematological Parametric Alterations in Indigenous Cattle Due to Trypanosomosis. Global Veterinaria, 9(5): 546-551.

[7] Degu, F., B. Ayalew, F. Tewodros and Ch. Mersha, 2012. Occurrence of Bovine Trypanosomosis, in the Blue Nile River Basin, Northwest Ethiopia.European Journal of Applied Sciences, 4(3): 129-135

[8] Dagnachew, S. and S. Shibeshi, 2006. Prevalence and vector distributions of bovine trypanosomosis in control (Sibu Sire) and noncontrol (Guto Gida) districts bordering upper Anger valley in East Wollega Zone, Western Ethiopia. Ethiopian Veterinary Journal, 15: 77-86

[9] Elnasri, H., 2005. Prevalence and Ranking of Bovine trypanosomiasis in Unity State, Sudan, MSc thesis, University of Khartoum, Faculty of Veterinary Medicine, Unity State, Sudanpp1-76

[10] Fimmen, H.O., D. Mehlitz, F. Horchiner and E. Korb, 1992. Colostral antibodies and Trypanosoma congolense infection in calves. Trypanotolerance research and application. GTZ, No.116, Germany, pp: 173-187.

[11] Ford, J. (1971). The role of trypanosomiasis in African ecology. Clarendon Press, Oxford, UK. pp 698.

[12] FAO (1992). Training manual for tsetse control personnel. FAO, Vol. 5, Rome, Italy

[13] Getachew A (2005). Trypanosomosis in Ethiopia, Addis Ababa University, Faculty of Veterinary Medicine. Debre Zeit, Ethiop. J. Biol Sci., 4(1): 75-121.

[14] Girma. K, Meseret .T, Tilahun. Z, Haimanot. D., Firew L,Tadele.K and Zelalem.A (2018): Prevalence of Bovine Trypanosomosis, its Vector Density and Distribution in and Around Arbaminch, Gamo Gofa Zone, Ethiopia. Acta Parasitologica Globalis 5 (3): 169-176.

[15] Itard, J. (1981). African animal trypanosomiasis. In: manual of tropical veterinary parasitology C.A.B.International,Nairobi,Kenya,79-291pp

[16] Kuzoe, F.A.S. (1991). "Perspectives in research on and control of African trypanosomiasis,"Annals of Tropical Medicine and Parasitology 85(1): 33-41

[17] Leak SGA, Woume KA, Colardeue C, Duffera W, Feron A, Mulingo M, Tikubet G, Toure M, Yangari G (1987). Determination of tsetse challenge and its relationship with trypanosomosis prevalence. In: livestock production in tsetse infested areas of Africa. Nairobi, Kenya, ATLN, pp. 43-52.

[18] Langridge, W. P. (1976). A tsetse and trypanosomiasis survey of Ethiopia. Ministry of overseas development, UK and Ministry of Agriculture of Ethiopia, 1-98pp.

[19] Ministry of Agriculture and Rural Development of the Government of Ethiopia (MoARD) (2004).

[20] Megersa Lemu, Feyisa Bekuma, Dereje Abera and Behablom Meharenet(2019). Prevalence of Bovine Trypanosomosis and Apparent Density of Tsetse Fly in Botor Tolay District, Jimma Zone, Ethiopia.InBiomedJSciandTechRes.

[21] Murray M, Trial TCM, Stephen LE (1983). Livestock productivity and trypanosomosis, ILCA, AddisAbaba, Ethiopia. 
Prevalence of Bovine Trypanosomosis its Associated Risk Factors, and Tsetse Density in Bonke Woreda, Gamo Zone, Ethiopia

[22] Mulligan, H. W. (1970). The African Trypanosomiasis. London: Allen and Unwin, 33-212 pp.

[23] Muturi, K.S., 1999. Epidemiology of bovine trypanosomosis in selected sites of the southern rift valley of Ethiopia, MSc Thesis, AAU, with freie Universitat, Berlin.

[24] Newstead, R., Evan, A. M. and Otts, W. H. (1924). Guide to study of tsetse Flies Memoirs of the Liverpool School of Tropical Medicine, University of Liverpool Press, Liverpool,UK 1-332pp.

[25] Nicholson, M.J. and M.H. Butterworth,. 1986. A Guide to condition scoring of zebu cattle. ILCA. LppDFID, pp: 1-29.

[26] Pollock, J. N. (1982). Training manual for tsetse control personnel, Ecology and behavior of tsetse. FAO, Rome. 2: 101.

[27] Paris J, Murray M, Agure R (1979). Report of the expert consultation on research of Trypanosomosis FAO. Rome.

[28] Radostits, O. and C. Gray, 2007. Veterinary Medicine: A text book of the disease of cattle, sheep, pigs, goats and horses, 10 ed., pp: 1424-1426. Baillier, th Tindall, London, England.

[29] Reid, R.S., R.L. Kruska, U. Deichmann, P.K. Thornton and S.G.A. Leak (1997). "Will human population growth and land-use change control tsetse during our lifetimes"Proceedings of the 24th Meeting of the International Scientific Council for Trypanosomiasis Research and Control (ISCTRC), Maputo, Mozambique, OAU/ISTRC, pp. 500-514.

[30] Sinshaw, A., G. Abebe, Desquesnes and W. Yoni, 2006. Biting flies and Trypanosoma vivax infection in three highland districts bordering lake Tana Ethiopia.Vet. Parasitol., 142: 35-46.

[31] Seifert SHH (1996). Tropical animal health; second edition, Dordrech: Kluwer Academic Publisher, pp. 78-170.

[32] Stephen LE (1986). Trypanosomosis a Veterinary Prospective program on Press Oxford.

[33] STEP (2013).Annual Reports of Southern Tsetse Eradication Project, Addis Ababa, Ethiopia.

[34] Soulsby, E.J.L. (1992). Helminths, Arthropods and Protozoa of Domestic Animals. 7th Edition. Buillier,Trindall. Pp 422-423.

[35] SRVL (2004). Annual Reports of Southern Regional State Veterinary Laboratory, Wolaita Sodo, Ethiopia.

[36] Tesfaye M (2002). Report of Trypanosome infection rate, in G.m.submoristans and G. tachinoides in Didessa Valley from July 29 to September 26/2002, Bedelle.

[37] Thrusfield M (2005). Veterinary Epidemiology, 2nd Edition. Blackwell Science Ltd., UK. pp. 182-198.

[38] Thomas and Berisha(2011):Manual on the biology and control of tsetse fly.

[39] Uilenberg, G., 1998. A field guide for the diagnosis, treatment and prevention of African animal Trypanosomosis. FAO, Rome, Italy, pp: 11-41

[40] Urquhart GM, Armour J, Duncan JL, Dunn AM, Jennings FW (1996). Veterinary parasitology 2nd edition. Black Well Science Ltd., London UK, pp. 212-219.

[41] Vale GA (1993). Development of baits for tsetse flies (Diptera:Glossinidae) in Zimbabwe. J. Med. Entomol., 30: 831- 842.

[42] Winrock International (1992). Assessment of Animal Agriculture in Subsaharan Africa. Winrock International.

[43] WHO(2000).world health organization annual report

Citation: Firew Lejebo, et.al., Prevalence of Bovine Trypanosomosis its Associated Risk Factors, and Tsetse Density in Bonke Woreda, Gamo Zone, Ethiopia. International Journal of Research Studies in Biosciences (IJRSB). 7(10), pp.1-12. DOI: http://dx.doi.org/10.20431/2349-4050.0710001

Copyright: (c) 2019 Authors This is an open-access article distributed under the terms of the Creative Commons Attribution License, which permits unrestricted use, distribution, and reproduction in any medium, provided the original author and source are credited. 